\title{
Differentially Localized Incorporation of Amino Acids in Relation to Epidermal Keratinization in the Newborn Rat'
}

\author{
KIMIE FUKUYAMA, TOSHIO NAKAMURA AND I. A. BERNSTEIN \\ Department of Dermatology, Tokyo Women's Medical College, Shinjuku-ku, \\ Tokyo, Japan, and Cellular Biochemistry Laboratory of the Departments \\ of Dermatology and Industrial Health and the Institute of Industrial \\ Health, The University of Michigan, Ann Arbor, Michigan
}

\begin{abstract}
Incorporation of tritiated methionine, phenylalanine, leucine, glycine and histidine into protein in the epidermis of the newborn rat was studied by autoradiography.

Methionine, phenylalanine and leucine behaved similarly. Thirty minutes after injection, radioactivity was detected in both nucleus and cytoplasm of the basal, spinous and granular cells with a greater intensity over the cells of the lower layer as compared with that observed over the upper layer. The label appeared over the cornified cells at 24 hours after injection probably as a result of the migration of cells into the cornified layer. In the case of glycine and histidine, the label was detected in each of the three layers at 30 minutes after injection but the labeling was higher in the upper part of the epidermis as compared with the lower part. The label appeared in the cornified layer six hours after injection. Processes possibly involved in formation of the cornified layer are discussed.
\end{abstract}

Synthesis of protein in epidermal cells of animals has been studied by autoradiography following administration of methionine- $S^{35}$ (Belanger, '56; Chekulaeva, '59; Edwards and Udupa, '57; Karpishka and Carneiro, '60; Leblond et al., '57), cystine$\mathrm{S}^{35}$ (Belanger, '56; Karpishka and Carneiro, '60; Pelc, '59), Bicarbonate-C ${ }^{14}$ (Greulich and Leblond, '53) and other labeled protein precursors. It has been considered that protein is synthesized in the cells of the deeper part of the epidermis, and that the radioactive protein then gradually moves with the cell towards the surface.

Ribonucleic acid is synthesized in the epidermis of the newborn rat in the cells of the basal, spinous and granular layers as evidenced by the incorporation of cytidine- $\mathrm{H}^{3}$ (Fukuyama and Bernstein, '63). This observation suggested the possibility that protein synthesis, de novo, might also occur in the cells of each of these three layers.

Since the relatively high beta energies of sulfur ${ }^{35}$ and carbon ${ }^{14}$ do not allow good autoradiographic localization of the incorporated tracer, the lower energy of the beta emitted by tritium would be expected to demonstrate the position of synthesis and metabolism of protein in the epidermis more precisely. Methionine- $\mathrm{H}^{3}$, leucine- $\mathrm{H}^{3}$, phenylalanine $-\mathrm{H}^{3}$, glycine- $\mathrm{H}^{3}$ and histidine$\mathrm{H}^{3}$ were therefore used in this investigation of protein synthesis in the epidermis of the newborn rat, in vivo. Autoradiographs indicated that the pattern of incorporation of the first three amino acids differed from that of glycine and histidine.

\section{MATERIALS AND METHODS}

Newborn rats (4-5-days-old) of the Sprague-Dawley strain were used. Groups of animals were injected intraperitoneally with $2 \mu \mathrm{c}$ of DL-methionine-methyl- $\mathrm{H}^{3}$ ( 10 $\mathrm{mc} / \mathrm{mmole}$ ), DL-leucine-4,5- $\mathrm{H}^{3}$ hydrochloride ( $300 \mathrm{mc} / \mathrm{mmole}$ ), DL-phenylalaninering- $\mathrm{H}^{3}$ hydrochloride $(20 \mathrm{mc} / \mathrm{mmole})$, glycine-2- $\mathrm{H}^{3}$ (labeled on the carbon) or Lhistidine $-\mathrm{H}^{3}$ (labeled on carbon 2 of the ring), per gram body weight. The tritiated compounds were administered at a level of $5 \mu \mathrm{c}$ per $0.01 \mathrm{ml}$ of distilled water. The animals were sacrificed at various times (up to 120 hours) after injection of the

1 Supported at Tokyo Women's College by Ajinomoto Co. and at The University of Michigan by contract Nonr 1224(35), NR 105-223 between the University of Michigan and the Office of Naval Research, U.S. Department of Defense. 
tracer and skin samples taken from the dorsal side of the animals were fixed in formolacetic acid alcohol. Some serial sections obtained from the animals injected with glycine- $\mathrm{H}^{3}$ were treated with DNase and RNase prior to preparation of autoradiographs.

After dehydration, the samples were embedded in paraffin and cut at $4 \mu$. Autoradiographs were prepared with Kodak Autoradiographic Stripping Plates, AR 10, and developed after four weeks of exposure. The sections were stained with methylene blue after development of the film.

\section{RESULTS}

Incorporation of methionine- $\mathrm{H}^{3}$, leucine$\mathrm{H}^{3}$ and phenylalanine- $\mathrm{H}^{3}$ was already seen in the epidermis at 30 minutes after injection of the respective tracers. At this time, the blackening of the emulsion was mainly over the basal and spinous cells, with some silver grains over the granular cells. At one hour after injection, the radioactivity was extensive over the basal and spinous layers and less extensive in the granular layer (figs. 1, 2,3). The radioactivity in the granular layer increased so that all layers of the epidermis were intensely labeled at six hours after injection. The isotopic distribution was similar in the nucleus and cytoplasm. The label started to appear on the cornified layer at 24 hours after injection (fig. 4). At two, three and four days, the amount of labeling over the cornified layer increased, and at five days this layer was intensely labeled (fig. 5). Detectable radioactivity remained in the basal, spinous and granular layers until the end of the experimental period.

Silver grains were also already present over the epidermis at 30 minutes after injection of glycine- $\mathrm{H}^{3}$ and histidine- $\mathrm{H}^{3}$ (figs. $6,7)$. Grains were located in the basal, spinous and granular layers, but the density of the labeling was higher in the upper part of the epidermis as compared with the lower part. The higher labeling in the upper layers is still evident at one hour (fig. 8). Very heavy incorporation was observed by the sixth hour. Both nucleus and cytoplasm were labeled and label was generally distributed over the positions of the keratohyalin granules (fig. 9).
In the cornified layer, the silver grains were first seen at six hours after injection of glycine- $\mathrm{H}^{3}$ and histidine- $\mathrm{H}^{3}$ (fig. 9). Sometimes, nuclear debris was seen in the area of such a group of grains, but nuclear and cell membranes were not visible in the area. At 12 hours after injection, more grains appeared intermittently in the lower part of the cornified layer (fig. 10), and at 24 hours the lower part of the cornified layer was continously labeled.

Sections taken from animals which had received glycine- $\mathrm{H}^{3}$ and incubated with DNase and RNase showed essentially the same density and distribution of radioactivity as serial sections not so treated (figs. $11,12)$.

\section{DISCUSSION}

The autoradiographs of this study are considered to represent labeled protein, although this has not been proven. The histological procedure would be expected to exclude free amino acids or small peptides. When sections taken one hour after the administration of glycine- $\mathrm{H}^{3}$ were incubated with RNase and DNase, no significant loss of labeling was observed confirming the fact that the incorporation of isotope in this case was not in nucleic acids. This was not suprising since glycine contributes its carbons to positions four and five in the adenine and guanine of nucleic acids (Sonne et al., '56) but neither of these carbons in these purines has an attached hydrogen. Kemp ('56) has shown that in the tissues of the frog there is a relationship between the total radioactivity seen by autoradiography and that found in the isolated protein after the administration of radioactive glycine. Skin was one of the tissues studied. It seems reasonable to assume that the autoradiographs obtained in this study represent the localization of labeled protein. If this assumption is valid, synthesis of protein occurs in cells of the basal, spinous and granular layers. It does not seem that protein synthesis in the skin of the newborn rat is restricted to a narrow zone of the epidermis, e.g., the basal layer, as suggested for the human epidermis (Rothberg et al., '61). The label seen in the upper spinous and granular layers at six hours in the experiments with labeled 
phenylalanine, leucine and methionine can not be a result of protein synthesis in the basal and lower spinous layers and movement of radioactive protein to the upper spinous and granular layers as a result of cell movement. A previous study (Fukuyama and Bernstein, '61) showed that it takes more than two days for cells to travel from the basal to the granular layer. In as much as cytidine- $\mathrm{H}^{3}$ is incorporated quickly into RNA at all cellular levels ( $\mathrm{Fu}-$ kuyama and Bernstein, '63), the present results appear to coincide with the hypothesis that active protein synthesis in tissue is associated with a high degree of RNA synthesis (Ficq, '59).

The observation made at six hours after injection showed the presence of radioactivity quite heavily throughout the epidermis. The fact that the density of grains over the epidermis at 24 hours was not significantly greater than that at six hours suggests that protein synthesis, from the injected radioactive amino acids, must have been ended by at least the sixth hour after administration of the tracer. This was probably a result of the disappearance of the labeled precursor.

The radiactivity which appeared in the cornified layer probably resulted from the displacement of the label from a lower part of the epidermis during the process of cell migration and cornification rather than from protein synthesis in the cornified layer. Labeling appeared in the stratum corneum earlier from those amino acids which labeled the granular cells earlier.

The difference in initial localization of the two groups of amino acids may be a result of (a) variations in size of the "pools" for the respective amino acids in the basal, spinous and granular layers, (b) regional differences in the types of protein being synthesized or (c) variations in the speed of movements of the individual amino acids to the more superficial layers. The most likely reason now appears to be a regional difference in the types of protein synthesized although this study does not eliminate the other two possibilities. In a separate investigation, Hoober and Bernstein ('63) isolated from the epidermis of the newborn rat, polypeptide material containing a high concentration of glycine, considerable histidine and little, or no, leucine, methionine or phenylalanine. When this polypeptide(s) was isolated one hour after administration of glycine $-\mathrm{H}^{3}$ or histidine- $\mathrm{H}^{3}$, but not phenylalanine- $\mathrm{H}^{3}$, it accounted for a great portion of the total radioactivity present in the epidermis. It seems possible that this polypeptide material is synthesized in the upper part of the epidermis to play a role in the keratinization process. Previous investigators have proposed that tonofilaments present in the cells of the deeper layers are precursors of keratin and that as the cell passes through the epidermis, from the basal to the granular layer, the filamentous structures are changed into the fibers of the cornified layer - probably with an accompanying molecular transformation, (Giround and Leblond, '51; Selby, '57; Zelickson and Hartmann, '61; Brody, '59). Thus Bern and his coworkers ('55) have reported that injected cystine- $\mathrm{S}^{35}$ incorporated into the tongue and the vaginal epidermis of mice in the region just under the cornified layer. The data were interpreted as "enrichment in sulfur" to produce "soft keratin" and it was suggested that much cystine may be added to the precursor protein in the granular cell as occurs in the keratogenous zone of hair. It would appear possible, then, that the formation of keratin involves two loci of amino acid incorporation in the epidermis - one in the deeper layers and one in the granular layer. Whether or not the protein newly synthesized in the granular cell, as observed in the present study, represents the incorporation of sulfur requires further investigation. The polypeptide material isolated by Hoober and Bernstein appears to have little or no sulfur, but the polypeptide (s) is attached to another protein molecule, in situ, and the latter may well include newly incorporated, sulfur-containing amino acids.

Electron microscopic studies on the keratinization of the epidermis have shown that during this process tonofibrils become arranged in a horizontal fashion, and keratohyalin granules appear in the granular cell, while the vital cytoplasmic organelles such as mitochondria, endoplasmic reticulum, Golgi apparatus, and melanin granules decrease in number. Selby ('57) and Flesh ('58) pose the idea that there is not 
a direct relationship between the keratohyalin granules and keratin, while Brody ('59) and Zelickson and Hartmann ('61) postulated that the keratohyalin granules surround the tonofibrils as the cells move toward the outer surface. The resolution allowed by autoradiography with the light microscope demonstrates that the incorporation of glycine- $\mathrm{H}^{3}$ and histidine $-\mathrm{H}^{3}$ is quite generally distributed in the cytoplasm of the granular cell. Since this cell is nearly filled with granules, it is therefore possible that the keratohyalin granules contain newly synthesized protein.

When label was seen in the cornified Iayer at six hours after injection of glycine$\mathrm{H}^{3}$ and histidine- $\mathrm{H}^{3}$, activated silver grains were localized and were concentrated in an area equivalent to that of one granular cell. This possibly represents the movement of one cell into the cornified layer from the granular layer. Even at 12 hours after injection when more label was found in the cornified layer, indicating that more cells had moved upwards, the distribution of radioactivity was still intermittent. These observations seem to demonstrate that the cell in the granular layer moves independently - i.e., as a single unit into the cornied layer just as the studies with thymidine- $\mathrm{H}^{3}$ (Fukuyama and Bernstein, '61) showed the cells to move into the spinous and granular layers from the basal layer. In histological sections, the epidermal cells appear to adhere to each other, but the cell structures do not continue from one cell to another and there is intercellular space between the two cells (Zelickson and Hartmann, '61). The epidermal cells may not be as rigidly attached as generally supposed, since they appear to be able to move individually.

At 24 hours after injection, the deepest part of the cornified layer was quite radioactive. The observation that incorporated glycine- $\mathrm{H}^{3}$ and histidine- $\mathrm{H}^{3}$ moved into the cornified layer earlier than did methionine$\mathrm{H}^{3}$, leucine- $\mathrm{H}^{3}$ and phenylalanine- $\mathrm{H}^{3}$ suggests that it is necessary to know the location in the epidermis of the early incorporation of a particular amino acid when one studies epidermal cell "turnover" by determining the appearance of radioactivity in the cornified material.
Further studies are required to determine whether or not these data are applicable to non-epidermal keratinization (e.g., hair) or even to epidermal keratinization in other species.

\section{LITERATURE CITED}

Belanger, L. F. 1956 Autoradiographic visualization of the entry and transit of $\mathrm{S}^{35}$ methionine and cystine in the soft and hard tissues of the growing rat. Anat. Rec., 124: 555-579.

Bern, H. A., D. R. Harkness and S. M. Blair 1955 Radioautographic studies of keratin formation. Proc. Natl. Acad. Sci., 41: 55-60.

Brody, I. 1959 An ultrastructural study on the role of the keratohyalin granules in the keratinization process. J. Ultrastruct. Res., 3: 84-104.

Chekulaeva, L. I. 1959 An investigation of the physiological regeneration of the epidermis and hair at different ages by the method of autoradiography. Bull. Exp. Biol. Med., 47: 246-250.

Edwards, L. C., and K. N. Udupa 1957 Autoradiographic determination of $\mathrm{S}^{35}$ in tissues after injection of methionine- $S^{35}$ and sodium sulfate- $\mathrm{S}^{35}$. J. Biophys. Biochem. Cytol., 3: $757-766$.

Ficq, A. 1959 Autoradiographic study of the relation between nucleic acids and protein synthesis. Lab. Invest, 8: 237-243.

Flesh, P. 1958 Chemical data on human epidermal keratinization and differentiation. J. Invest. Derm., 31: 63-73.

Fukuyama, K., and I. A. Bernstein 1961 Autoradiographic studies of the incorporation of thymidine- $\mathrm{H}^{3}$ into deoxyribonucleic acid in the skin of young rats. J. Invest. Derm., 36: 321-326.

1963 Site of synthesis of ribonucleic acid in mammalian epidermis. J. Invest. Derm., 41: 47--52.

Giround, A., and C. P. Leblond 1951 The keratinization of epidermis and its derivatives especially the hair, as shown by x-ray diffraction and histochemical studies. Ann. N. Y. Acad. Sci., 53: 613-626.

Greulich, R. C., and C. P. Leblond 1953 Radioautographic visualization of radiocarbon in the organs and tissues of newborn rats following administration of $\mathrm{C}^{14}$-labeled bicarbonate. Anat. Rec., 115: 559-585.

Hoober, K., and I. A. Bernstein 1963 Studies on the mechanism of the localized incorporation of glycine- $\mathrm{H}^{3}$ in newborn rat epidermis. Federation Proc., 22: 238.

Karpishka, I., and J. Carneiro 1960 Incorporation of three methionine labels, radioautographic comparison of the sites of $\mathrm{C}^{14}, \mathrm{~S}^{35}$ and $\mathrm{H}^{3}$. Anat. Rec., 137: 73-85.

Kemp, N. E. 1956 Localization of glycine-2-C ${ }^{14}$ injected into adult female frogs. J. Exp. Zool., 133: 227-239.

Leblond, C. P., N. B. Everett and B. Simmons 1957 Sites of protein synthesis as shown by 
radioautography after administration of $\mathrm{S}^{35}$ labeled methionine, Am. J. Anat,, 101: 225271.

Pelc, S. R. 1959 Metabolic activity of DNA as shown by autoradiographs. Lab. Invest., 8: $225-236$.

Rothberg, S., R. C. Crounse and J. L. Lee 1961 Glycine-C ${ }^{14}$ incorporation into the proteins of normal stratum corneum and abnormal stratum corneum of psoriasis. J. Invest. Derm., 37: $497-504$.
Selby, C. C. 1957 An electron microscope study of thin sections of human skin. II. Superficial cell layers of foot pad epidermis. J. Invest. Derm., 29: 131-149.

Sonne, J. C., I. Lin and J. M. Buchanan 1956 Biosynthesis of the purines. IX. Precursors of the nitrogen atoms of the purine ring. J. Biol. Chem., 220: 369-377.

Zelickson, A. S., and J. F. Hartmann 1951 An electron microscopic study of human epidermis. J. Invest. Derm., 36: 65-72. 
PLATE 1

EXPLANATION OF FIGURES

1 Incorporation of methionine- $\mathrm{H}^{3}$ one hour after injection.

2 Incorporation of phenylalanine- $\mathrm{H}^{3}$ one hour after injection.

3 Incorporation of leucine- $\mathrm{H}^{3}$ one hour after injection.

4 Incorporation of methionine- $\mathrm{H}^{3} 24$ hours after injection. 

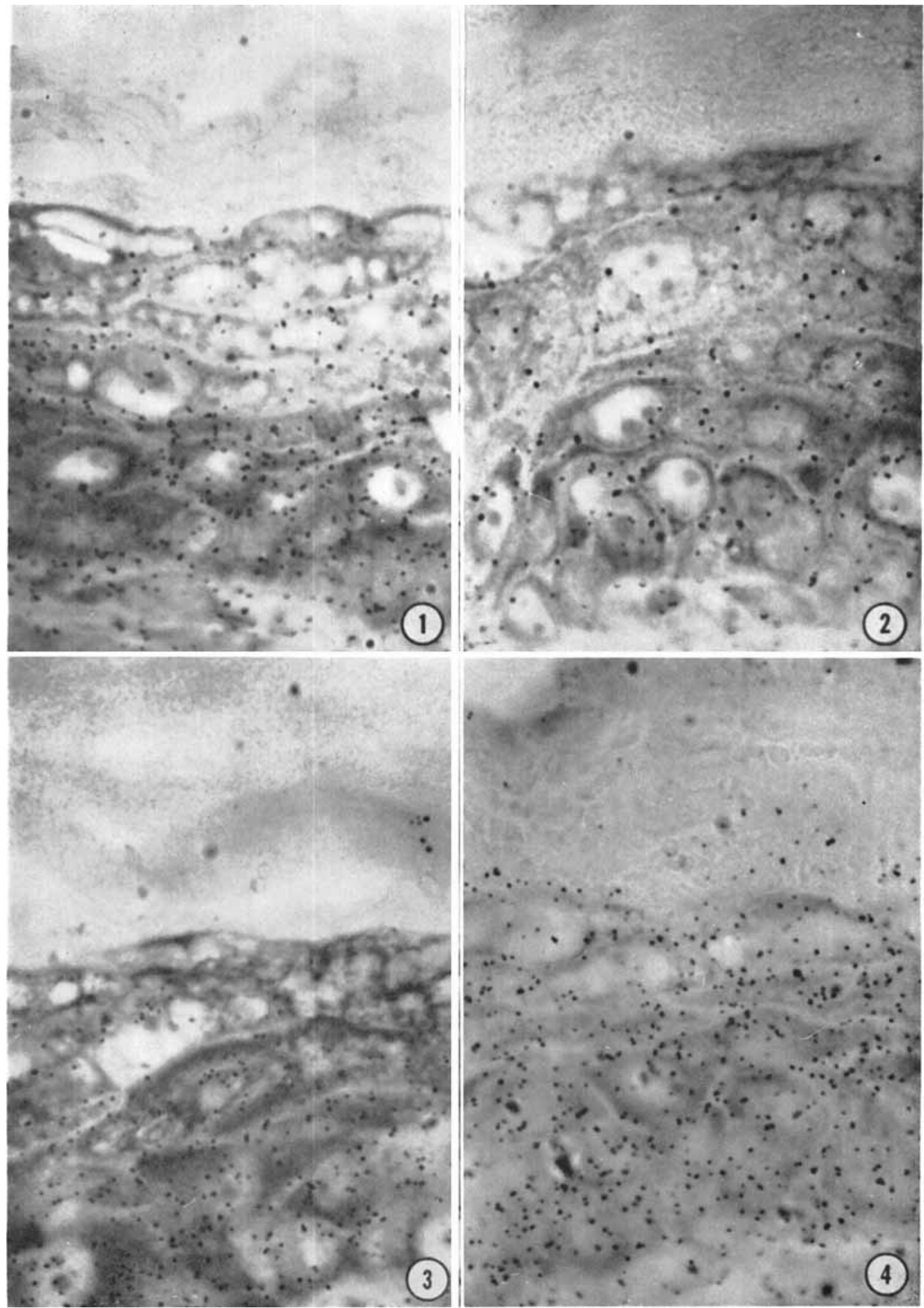
PLATE 2

EXPLANATION OF FIGURES

5 Incorporation of phenylalanine- $\mathrm{H}^{3} 120$ hours after injection.

6 Incorporation of glycine- $\mathrm{H}^{3}$ one half hour after injection.

7 Incorporation of histidine- $\mathrm{H}^{3}$ one half hour after injection.

8 Incorporation of histidine- $\mathrm{H}^{3}$ one hour after injection. 
EPIDERMAL AMINO ACID INCORPORATION

PLATE 2

Kimie Fukuyama, Toshio Nakamura and I. A. Bernstein

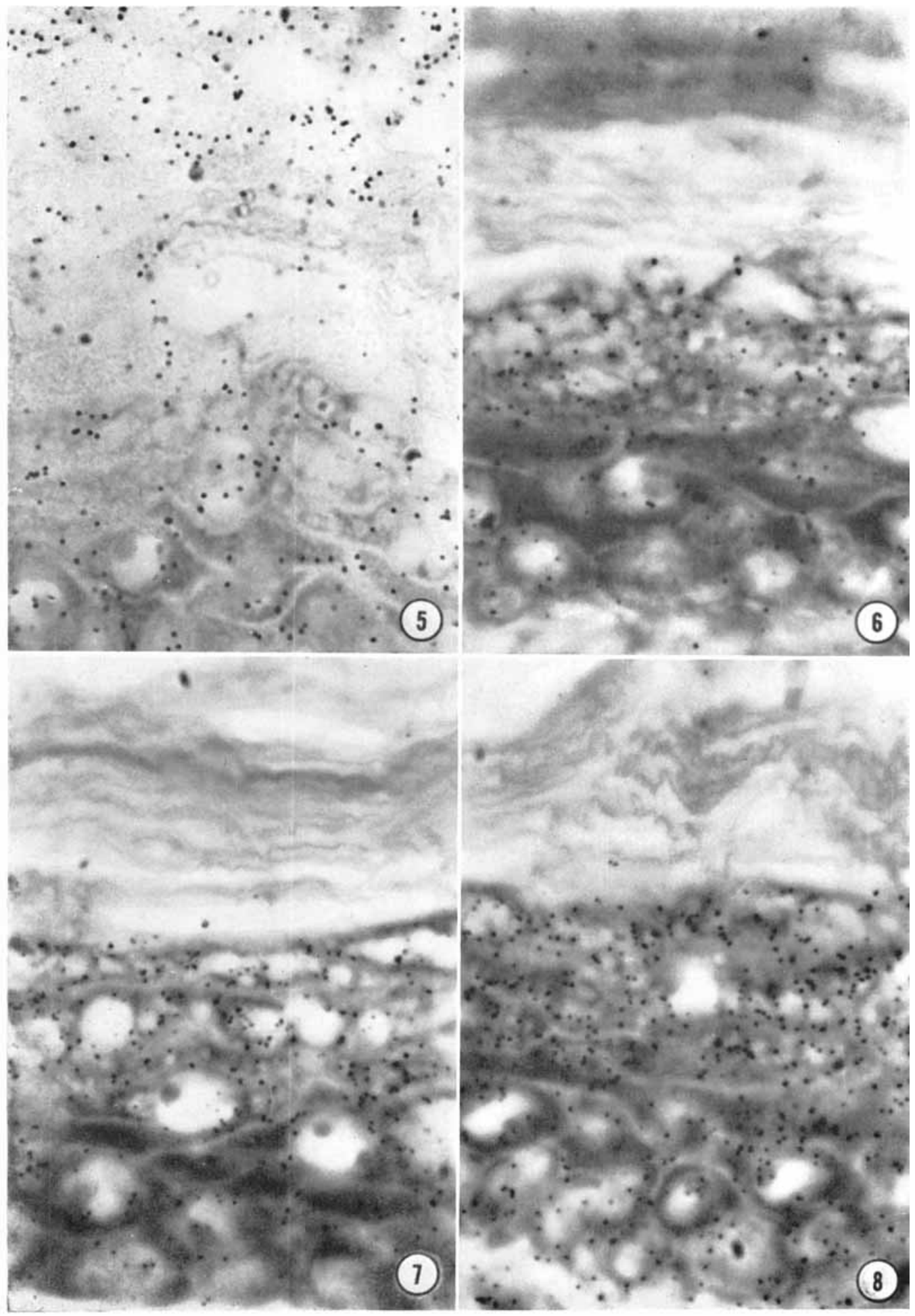


PLATE 3

EXPLANATION OF FIGURES

9 Incorporation of histidine- $\mathrm{H}^{3}$ six hours after injection.

10 Incorporation of glycine- $\mathrm{H}^{3} 12$ hours after injection.

11 Incorporation of glycine- $\mathrm{H}^{3}$ one hour after incorporation. Section has been treated with RNase.

12 Incorporation of glycine- $\mathrm{H}^{3}$ one hour after incorporation. Section has been treated with DNase. 

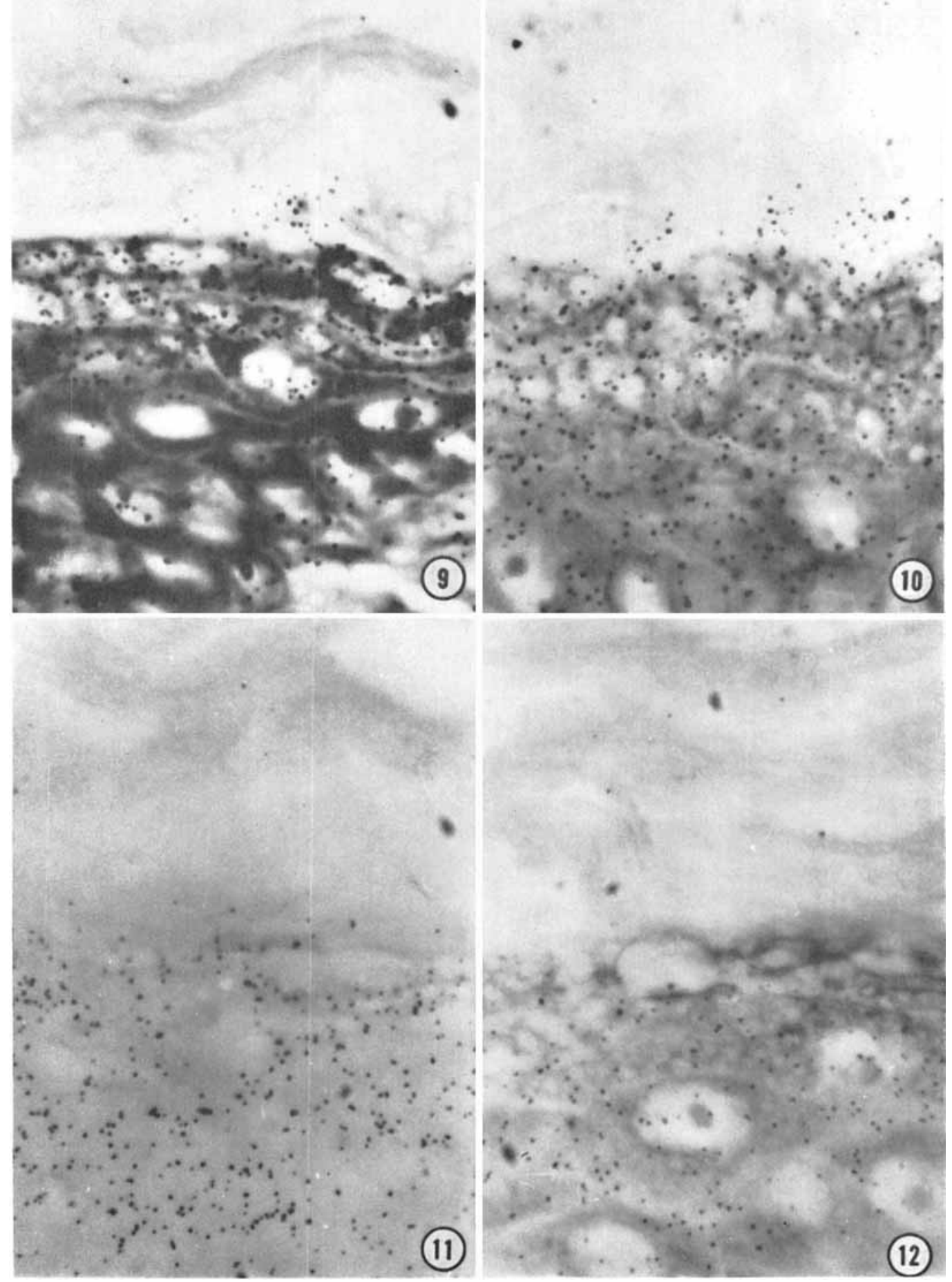